OPEN ACCESS

Edited by: Joseph O. Fadare,

Ekiti State University, Nigeria

Reviewed by:

Tanveer Ahmed Khan,

National Institute of Health, Pakistan

Brian Godman,

Karolinska Institutet (KI), Sweden

${ }^{*}$ Correspondence:

Muhammad Salman

muhammad.salman@

pharm.uol.edu.pk;

msk5012@gmail.com

Specialty section:

This article was submitted to Pharmaceutical Medicine and Outcomes Research,

a section of the journal

Frontiers in Pharmacology

Received: 12 December 2019 Accepted: 24 June 2020

Published: 14 July 2020

Citation:

Salman M, Mustafa ZU, Rao AZ,

Khan Q-U-A, Asif N, Hussain K, Shehzadi N, Khan MFA and Rashid A (2020) Serious Inadequacies in High Alert Medication-Related Knowledge

Among Pakistani Nurses:

Findings of a Large, Multicenter, Cross-sectional Survey.

Front. Pharmacol. 11:1026. doi: 10.3389/fphar.2020.01026

\section{Serious Inadequacies in High Alert Medication-Related Knowledge Among Pakistani Nurses: Findings of a Large, Multicenter, Cross-sectional Survey}

\author{
Muhammad Salman ${ }^{1 *}$, Zia UI Mustafa ${ }^{2}$, Alina Zeeshan Rao ${ }^{3}$, Qurat-ul-Ain Khan ${ }^{4}$, \\ Noman Asif ${ }^{3}$, Khalid Hussain ${ }^{3}$, Naureen Shehzadi ${ }^{3}$, Muhammad Farhan Ali Khan ${ }^{5}$ \\ and Amir Rashid ${ }^{6}$
}

1 Department of Pharmacy Practice, Faculty of Pharmacy, The University of Lahore, Lahore, Pakistan, 2 Department of Pharmacy, District Headquarter Hospital, Pakpattan, Pakistan, ${ }^{3}$ Punjab University College of Pharmacy, University of the Punjab, Lahore, Pakistan, ${ }^{4}$ Department of Pharmacy, Punjab Institute of Cardiology, Lahore, Pakistan, ${ }^{5}$ Department of Pharmacy, Quaid-i-Azam University, Islamabad, Pakistan, ${ }^{6}$ Department of Pharmacology, Faculty of Pharmacy, The University of Lahore, Islamabad, Pakistan

Introduction: Deaths-related to medications errors are common in Pakistan but these are not accurately reported. Recently, the death of a 9 months old baby due to abrupt administration of $15 \%$ potassium chloride injection sparked the issue of high alert medications (HAMs) related errors in the country. Since drug administration is the prime responsibility of the nurses, it is pivotal that they possess good knowledge of HAMs. Since there is no published data regarding the knowledge of HAMs among Pakistani nurses, we aimed to assess knowledge of HAMs among registered nurses of Pakistan.

Methods: A cross-sectional study was conducted among registered nurses, recruited using a convenient sampling technique, from 29 hospitals all over the Punjab Province. Data were collected using a validated self-administered instrument. All data were entered and analyzed using SPSS version 22.

Results: The study sample was comprised of 2,363 registered nurses (staff nurses = $94.8 \%$, head nurses $=5.2 \%$ ). Around $63 \%$ were working in tertiary hospitals whereas almost 25 and 12\% were from district headquarter hospitals and tehsil headquarter hospitals, respectively. Around $84 \%$ of the study participants achieved scores $<70 \%$, indicating majority of Pakistani nurses having poor knowledge of HAMs administration as well as regulation. There was no significant difference of overall knowledge among age, hospitals, departments, training, designations, qualification, and experience categories. Major obstacles encountered during HAMs administration were "getting uncertain answers from colleagues" (72.9\%), "unavailability of suitable person to consult" (61.1\%) and "receiving verbal orders" (55.6\%).

Conclusion: Our study revealed the serious inadequacies in HAMs knowledge among Pakistani nurses which may lead to adverse patient outcomes. Nurses should receive 
comprehensive pharmacology knowledge not only during in-school nursing education but also as hospital-based continuing education. Moreover, it is of immense importance to bridge the gaps between physicians, clinical pharmacists, and nurses through effective communication as this will help reduce medication errors and improve patient care.

Keywords: barriers, high alert medications, knowledge, nurses, Pakistan

\section{INTRODUCTION}

Medication error is defined as "any preventable event that may cause or lead to inappropriate medication use or patient harm while the medication is in the control of the health professional, patient, or consumer. Such events may be related to professional practice, health care products, procedures, and systems, including prescribing, order communication, product labeling, packaging, and nomenclature, compounding, dispensing, distribution, administration, education, monitoring, and use" (NCCMERP, 2015). There are several ways to classify these errors. One way is to classify these errors in the sequence of medication use process: prescribing, transcribing, dispensing, administration, or monitoring (WHO, 2016). Another approach is to classify them according to whether they occur from mistakes in planning actions (knowledge-based or rulebased errors) or errors in carrying out an action (action-based errors, also called "slips," or memory-based errors, also called "lapses") (Ferner and Aronson, 2006; Aronson, 2009). A further approach is to classify medication errors as wrong patient, medication, dose, frequency, duration, and route of administration (WHO, 2016). Medication errors pose life threatening risk to the patient and a high economic loss (Perrone et al., 2014; Tshiamo et al., 2015; Akhideno et al., 2018; Formica et al., 2018). Medication error is the prime patient safety and quality care concern nowadays. Globally, 2-5\% hospital admissions are due to medication errors and most of them are preventable (Roughead et al., 2013; Perrone et al., 2014; AHRQ, 2015; Latimer et al., 2017; Iftikhar et al., 2018). According to the statistics of Centers for Disease Control and Prevention, medications errors are the third leading cause of mortality in United States with 98,000 deaths per annum (Pham et al., 2012; Makary and Daniel, 2016).

High alert medications (HAMs) cause serious health injuries or even death to the patient if use improperly. As compared to ordinary drugs, HAMs carry greater risks of adverse events (Labib et al., 2018; Shen et al., 2018). The American Pharmaceutical Association categorizes HAMs into following classes, chemotherapeutic agents, cardiovascular medications, anticoagulants, opioids and their derivatives, neuromuscular blocking agents, benzodiazepines, and some electrolytes like potassium chloride (15\%) (Zyoud et al., 2019). Majorly, these medications are used in acute and emergency rooms. Others places of HAMs usage are intensive care unit, coronary care unit, hemodialysis unit, pediatrics ward, medical ward, as well in labor room and surgical ward.

Nurses are the nucleus of health care system. Being a vital member of health care provision team, they are actively involved in patient care. Administration of drug to the particular patient according to the prescriber's order is one of the most crucial tasks performed by nursing staff. Unlike the other health care team members, nurses are always in close contact with the patient throughout the course of their treatment. Therefore, they are well aware about the actual condition of patient before and after drug administration and can actively report adverse drug reactions. The most common nursing-associated medication errors are related to administrations of drugs (Choi et al., 2016). Published data showed that the major reasons of medication administration errors by nurses are related to medication packaging e.g. similarities in packaging, appearance and names (Mrayyan et al., 2007; Dumo, 2012; Mrayyan, 2012; Hammoudi et al., 2018), and poor communication between physicians and nurses (Kim et al., 2011; Dumo, 2012; Topcu et al., 2017; Hammoudi et al., 2017). With regards to the barriers of medication errors reporting, important factors are the administrator's responses to medication errors, fear, reporting efforts, disagreements on the definitions of errors (Chiang et al., 2010; Petrova et al., 2010; Kim et al., 2011; Aboshaiqah, 2013; Shamim et al., 2016; Hammoudi et al., 2018). Pakistan is a resourcelimited country where disease burden is very high. The current status of country's health care system is worrying. Deaths due to medications errors are common but these are not reported due to the lack of required mechanism and fear of patient relatives' reaction or adverse career-related repercussions (DAWN News, 2017). Recently, the death of a 9 months old baby in a private sector hospital of Karachi (Capital city of Sindh, Pakistan) due to abrupt administration of $15 \%$ potassium chloride $(\mathrm{KCl})$ injection had highlighted the issue of high alert related medication errors in the country (Jafferi, 2019; Geo News, 2019; 92 News, 2019). According to the Pakistan economic survey 2017-2018, 108,474 registered nurses were performing duties across the country (FDGOP, 2019). Their awareness about the high alert medication is of vital importance as these drugs possess greater potential to cause serious consequences, if administered inappropriately. To the best of our knowledge and literature survey, there is no published data regarding the knowledge of HAMs among registered Pakistani nurses. Therefore, current study was carried out to estimate the knowledge about administration and regulation of HAMs among registered nurses of Pakistan. Moreover, the possible barriers faced in the administration of HAMs were also evaluated.

\section{METHODS}

\section{Study Design and Setting}

This cross-sectional study was conducted among the registered nurses from four metropolitan divisions of province Punjab 
namely Sahiwal, Multan, Faisalabad, and Lahore. The data were obtained from 29 health care settings (Secondary and tertiary care hospitals), including 11 tertiary/teaching hospitals, 9 District Head Quarter (DHQ) hospitals, and 9 Tehsil Head Quarter (THQ) hospitals during a period of 6 months (FebJuly 2019). A convenient sampling technique was employed and trained investigators approached the nursing staff in the abovementioned hospitals and briefed them about the intent of this study. Those who were willing to be enrolled were administered the study questionnaire.

\section{Ethical Approval}

Protocol of the current study was reviewed and approved by the Research Ethics Committee of the Department of Pharmacy Practice, Faculty of Pharmacy, The University of Lahore (REC/ DPP/FOP/10A). Additionally, written requests, along with documents, were submitted and approvals were obtained from relevant authorities at study sites. The research was conducted in accordance with ethical principles laid down in the 1964 Declaration of Helsinki and its later amendments. As the committee waived the need for written consent, a verbal informed consent was obtained from every nurse before the enrollment and all the participants were ensured about the confidentiality of their responses.

\section{Inclusion and Exclusion Criteria}

The nursing staff registered under the Pakistan nursing council, currently providing services in the emergency room, intensive care unit, dialysis unit, cardiac ward, pediatrics ward, medical ward, obstetrics and gynecology ward, surgical ward, operation theatre, and labor room of the afore-mentioned public sector hospitals were included in the current study. These wards were selected as they carry high risk of errors. Nursing students or nurses working in private sector as well as in the departments other than those mentioned above were excluded from this study.

\section{Study Instrument}

In the present study, a self-administered questionnaire developed by Hsaio et al. (2010) was used to determine HAM-related knowledge of nurses (Appendix). This instrument was in English as all the nursing curriculum in Pakistan are taught in English so there was no need for translation into Urdu language. The study instrument had four sections. Sections 1 had 10-items to gather demographics details. Sections 2 and 3 had 10-items each to assess knowledge of HAM administration and regulation, respectively. Each correct response was given 1 score while incorrect or don't know response were scored 0. Therefore, total knowledge score of HAM administration and regulation was 10 each. To calculate overall HAM-related knowledge score, each correct answer in sections 2 and 3 (total of 20 questions) was given five points, with a total score of 100; incorrect or don't know answers were scored zero. Knowledge scores were classified as good knowledge $\geq 70 \%$, or poor knowledge $<70 \%$.

A pilot study was conducted in twenty nurses to check the clarity and understandability of all the questions in the study instrument. All participants responded that questions were clear and they were able to understand them all.

\section{Statistical Analysis}

Categorical data were presented as number with percentages. Results of Shapiro-Wilk test revealed the non-normal distribution of continuous variables. Therefore, continuous variables were presented as medians and 25th and 75th percentiles. Continuous data were compared between two groups using the Mann-Whitney $U$ test, and between more than two groups using the Kruskal-Wallis $\mathrm{H}$ test. Categorical data were compared using the chi-square test. All statistical analyses were performed using SPSS version 22 for Windows. A p value of less than 0.05 was considered statistically significant.

\section{RESULTS}

A total of 2,500 registered nurses were approached by the investigators and received completely filled study instrument from 2,363 with a response rate of $94.5 \%$.

\section{Demographic Characteristics}

Demographic data of the study participants are shown in Table $\mathbf{1 .}$ Our study sample was comprised of only females (staff nurses = $94.8 \%$, head nurses $=5.2 \%$ ), with majority of nurses between 26 and 30 years (36.1\%) of age followed by $31-35$ years (29.2\%). Around $63 \%$ were working in teaching hospitals whereas almost 25 and 12\% from DHQ and THQ hospitals, respectively. Majority of nurses (37\%) were providing services in the Acute \& Emergency departments followed by cardiology (16.4\%) and gynecology (11.4\%).

\section{Nurses' Knowledge of High Alert Medication Administration}

Responses to the questions related to HAMs administration are presented in Table 2. The median (25th and 75th percentile) knowledge score of HAMs administration was 6 (5 and 7). There was no significant difference $(\mathrm{P}>0.05)$ of knowledge scores related to HAMs administration among categories of age, hospitals, departments, training, designations, qualification, and experience.

\section{Nurses' Knowledge of High Alert Medication Regulation}

Participants' responses to the items regarding the regulation of high risk medications are presented in Table 3. The median (25th and 75th percentile) knowledge score of HAMs regulation was 5 (4 and 6). No significant difference of knowledge scores related to HAM regulation was seen among age, departments, training, designations, qualification, and experience categories. However, a statistically significant difference was found among hospital categories. In post hoc analysis using Bonferroni correction, only the nurses from DHQ hospitals were found to have significantly less knowledge of HAMs regulation than those working in teaching hospitals $(\mathrm{p}=0.003)$.

\section{Overall Knowledge Related to High Alert Medications}

Around $84 \%$ of the study participants achieved scores $<70 \%$, indicating majority of Pakistani nurses having poor knowledge of HAMs administration as well as regulation. Chi-square tests 
TABLE 1 | Demographic details of the study participants.

\begin{tabular}{|c|c|c|}
\hline Variables & $\mathbf{N}$ & $\%$ \\
\hline \multicolumn{3}{|l|}{ Age (years) } \\
\hline$\leq 25$ & 494 & 20.9 \\
\hline$>25-30$ & 852 & 36.1 \\
\hline$>30-35$ & 689 & 29.2 \\
\hline$>35$ & 328 & 13.9 \\
\hline \multicolumn{3}{|l|}{ Hospital type } \\
\hline THQ hospital & 292 & 12.4 \\
\hline DHQ hospital & 588 & 24.9 \\
\hline Teaching hospital & 1,483 & 62.8 \\
\hline \multicolumn{3}{|l|}{ Working department } \\
\hline Cardiac & 387 & 16.4 \\
\hline Dialysis & 148 & 6.3 \\
\hline Emergency & 875 & 37.0 \\
\hline Obstetrics and gynecology & 277 & 11.7 \\
\hline Labor room & 87 & 3.7 \\
\hline Medical & 238 & 10.1 \\
\hline Operation theater & 195 & 8.2 \\
\hline Pediatric & 140 & 5.9 \\
\hline Surgery & 16 & 0.7 \\
\hline \multicolumn{3}{|l|}{ Training } \\
\hline Basic life support & 164 & 6.9 \\
\hline Emergency room training & 414 & 17.5 \\
\hline Infection control & 477 & 20.2 \\
\hline Midwifery & 167 & 7.1 \\
\hline Operation theater & 77 & 3.3 \\
\hline Personal protective equipment & 169 & 7.1 \\
\hline Nursery (Neonatal ICU) & 83 & 3.5 \\
\hline No training & 812 & 34.3 \\
\hline \multicolumn{3}{|l|}{ Qualification } \\
\hline Bachelor & 2,276 & 96.3 \\
\hline Master & 87 & 3.7 \\
\hline \multicolumn{3}{|l|}{ Designation } \\
\hline Staff nurse & 2,240 & 94.8 \\
\hline Head nurse & 123 & 5.2 \\
\hline \multicolumn{3}{|l|}{ Experience (years) } \\
\hline$\leq 2$ & 465 & 19.7 \\
\hline$>2-4$ & 755 & 32.0 \\
\hline$>4-6$ & 228 & 9.6 \\
\hline$>6-8$ & 206 & 8.7 \\
\hline$>8-10$ & 152 & 6.4 \\
\hline$>10$ & 557 & 23.6 \\
\hline
\end{tabular}

DHQ, District Headquarter; THQ, Tertiary Headquarter.

revealed that there was no significant difference of knowledge among different demographic variables (age, hospitals, departments, training, designations, qualification, and experience).

\section{Barriers Encountered During High Alert Medications Administration}

Obstacles that nurses encounter during HAMs administration are shown in Table 4. Major barriers related to HAMs administration were "getting uncertain answers from colleagues" (72.9\%), "unavailability of suitable person to consult" (61.1\%), and "receiving verbal orders" (55.6\%).

\section{DISCUSSION}

This is the first ever study that provided insight not only about the knowledge of HAMs administration and regulation among Pakistani nurses but also the barriers encountered during
TABLE 2 | Knowledge of High Alert Medications administration.

\begin{tabular}{|c|c|c|c|c|}
\hline \multirow[t]{2}{*}{ No. } & \multirow[t]{2}{*}{ Questions } & \multirow[t]{2}{*}{ Answers } & \multirow{2}{*}{$\frac{\text { Correct }}{\mathrm{N}(\%)}$} & \multirow{2}{*}{$\frac{\text { Incorrect }}{\mathrm{N}(\%)}$} \\
\hline & & & & \\
\hline 1 & $\begin{array}{l}\text { Fast intravenous push of } 1: 1000 \\
\text { epinephrine } 1 \text { ampule for patient who has } \\
\text { mild allergic reaction }\end{array}$ & False & $\begin{array}{l}1,578 \\
(66.8)\end{array}$ & $\begin{array}{c}728 \\
(33.2)\end{array}$ \\
\hline 2 & $\begin{array}{l}\text { When an emergency happens, } \\
\text { administer } 10 \% \text { calcium chloride }\left(\mathrm{CaCl}_{2}\right) \\
10 \mathrm{ml} \text { as a fast intravenous push (in } 1-2 \\
\text { minutes) }\end{array}$ & False & $\begin{array}{l}1,726 \\
(66.6)\end{array}$ & $\begin{array}{c}638 \\
(27.0)\end{array}$ \\
\hline 3 & $\begin{array}{l}10 \% \text { calcium gluconate and } 10 \% \mathrm{CaCl}_{2} \\
\text { are the same drug and are } \\
\text { interchangeable }\end{array}$ & False & $\begin{array}{l}1,491 \\
(63.1)\end{array}$ & $\begin{array}{c}873 \\
(36.9)\end{array}$ \\
\hline 4 & $\begin{array}{l}\text { Dosage expression for insulin injection is } \\
\text { "cc" or "ml" }\end{array}$ & False & $\begin{array}{l}1,381 \\
(58.4)\end{array}$ & $\begin{array}{c}983 \\
(41.6)\end{array}$ \\
\hline 5 & $\begin{array}{l}\text { Accurate chemotherapy dose calculation } \\
\text { for adults is based on body weight } \\
\text { whereas chemotherapy for children is } \\
\text { based on body surface area }\end{array}$ & False & $\begin{array}{l}1,446 \\
(61.2)\end{array}$ & $\begin{array}{c}917 \\
(38.8)\end{array}$ \\
\hline 6 & $\begin{array}{l}\text { When an emergency such as ventricular } \\
\text { fibrillation happens, push fast 15\% } \\
\text { potassium chloride (KCl) } 10 \mathrm{ml} \\
\text { intravenously }\end{array}$ & False & $\begin{array}{l}1,502 \\
(63.5)\end{array}$ & $\begin{array}{c}862 \\
(36.5)\end{array}$ \\
\hline 7 & $\begin{array}{l}15 \% \mathrm{KCl} \text { is better be added to Ringer's } \\
\text { solution for rapid infusion }\end{array}$ & False & $\begin{array}{l}1,485 \\
(62.8)\end{array}$ & $\begin{array}{c}878 \\
(37.2)\end{array}$ \\
\hline 8 & $\begin{array}{l}\text { Insulin syringe can be replaced by } 1 \mathrm{ml} \\
\text { syringe }\end{array}$ & False & $\begin{array}{c}942 \\
(39.8)\end{array}$ & $\begin{array}{l}1,421 \\
(60.1)\end{array}$ \\
\hline 9 & $\begin{array}{l}\text { Give fast IV infusion of } 3 \% \mathrm{NaCl} 500 \mathrm{ml} \\
\text { for patient who has low sodium level }\end{array}$ & False & $\begin{array}{l}1,298 \\
(54.9)\end{array}$ & $\begin{array}{l}1,065 \\
(45.1)\end{array}$ \\
\hline 10 & $\begin{array}{l}\text { Port-A route can be used for blood } \\
\text { withdrawal and drug injection generally }\end{array}$ & False & $\begin{array}{l}1,431 \\
(60.6)\end{array}$ & $\begin{array}{c}932 \\
(39.4)\end{array}$ \\
\hline
\end{tabular}

administration of these medications. Our findings revealed that majority of nurses were found to have inadequate knowledge of HAMs which was comparable to the findings from Taiwan (Hsaio et al., 2010) and Palestine (Zyoud et al., 2019). Adrenaline should preferably administered via intramuscular route and IV route to be reserved only for extreme emergency in the presence of trained physician. Around one third of the nursing staff did not choose the right answer of adrenaline administration which was comparable to the findings of Hsaio et al. (2010) and Zyoud et al. (2019). Concentrated electrolyte solutions like $\mathrm{KCl}(15 \%)$, calcium chloride $\left(\mathrm{CaCl}_{2}\right)$, and hypertonic saline should not be administer via IV push due to greater risk of complications. Incorrect IV administration of $\mathrm{KCl}$ (15\%) causes adverse events like arrhythmias and cardiac arrest leading to patient's death as documented in the previous studies (Reeve et al., 2005; Bonvin et al., 2009). Similarly, inappropriate administration of hypertonic saline cause phlebitis, extravasation injuries, and hypernatremia resulting in hypertensive emergencies especially in cardiac patients (Dillon et al., 2018). Administration of calcium salts via fast IV push is also associated with significant adverse events (Anger et al., 2014). The current study revealed that one third of the study population did not give correct response regarding $15 \% \mathrm{KCl}$ and $10 \% \mathrm{CaCl}_{2}$ administration, which was similar to the findings of a study conducted in Palestinian Nurses (Zyoud et al., 2019). Shockingly, around $39 \%$ of the study participants gave incorrect response about the dose calculation in children and cancerous patients. Likewise, Lan et al. also reported that knowledge of Taiwanese 
TABLE 3 | Nurses' knowledge of high alert medications regulation.

\begin{tabular}{|c|c|c|c|c|}
\hline \multirow[t]{2}{*}{ No. } & \multirow[t]{2}{*}{ Questions } & \multirow{2}{*}{ Answers } & \multirow{2}{*}{$\frac{\text { Correct }}{N(\%)}$} & \multirow{2}{*}{$\frac{\text { Incorrect }}{\mathrm{N}(\%)}$} \\
\hline & & & & \\
\hline 1 & $\begin{array}{l}\text { It is better to use "Amp" or "Vial" for dose } \\
\text { expression instead of "mg" or "gm" }\end{array}$ & False & $\begin{array}{l}1,645 \\
(69.6)\end{array}$ & $\begin{array}{c}718 \\
(30.4)\end{array}$ \\
\hline 2 & $\begin{array}{l}\text { Distinctive labeling should be used on } \\
\text { look-alike drugs }\end{array}$ & True & $\begin{array}{l}1,564 \\
(66.2)\end{array}$ & $\begin{array}{c}799 \\
(33.8)\end{array}$ \\
\hline 3 & $\begin{array}{l}\text { It is right to use " } U \text { " instead of unit for } \\
\text { dose expression }\end{array}$ & False & $\begin{array}{l}1,834 \\
(77.6)\end{array}$ & $\begin{array}{c}529 \\
(22.4)\end{array}$ \\
\hline 4 & $\begin{array}{l}\text { For convenience, heparin and insulin } \\
\text { should be stored together in the } \\
\text { refrigerator }\end{array}$ & False & $\begin{array}{l}1,842 \\
(77.9)\end{array}$ & $\begin{array}{c}522 \\
(22.1)\end{array}$ \\
\hline 5 & $\begin{array}{l}\text { Each drug better have multiple } \\
\text { concentrations for nurse to choose }\end{array}$ & False & $\begin{array}{l}1,432 \\
(60.6)\end{array}$ & $\begin{array}{c}931 \\
(39.4)\end{array}$ \\
\hline 6 & $\begin{array}{l}\text { If a patient can tolerate, potassium can } \\
\text { be administered orally instead of IV route }\end{array}$ & True & $\begin{array}{c}395 \\
(16.7)\end{array}$ & $\begin{array}{l}1,968 \\
(83.8)\end{array}$ \\
\hline 7 & $\begin{array}{l}15 \% \mathrm{KCl} \text { is frequently used, so it should } \\
\text { be easily and freely accessed by nurses }\end{array}$ & False & $\begin{array}{l}1,292 \\
(54.7)\end{array}$ & $\begin{array}{l}1,071 \\
(45.3)\end{array}$ \\
\hline 8 & $\begin{array}{l}\text { For pediatric dose, use teaspoon for } \\
\text { dose expression }\end{array}$ & False & $\begin{array}{c}450 \\
(19.0)\end{array}$ & $\begin{array}{l}1,913 \\
(81.0)\end{array}$ \\
\hline 9 & $\begin{array}{l}\text { Fentanyl skin patch is a controlled } \\
\text { medicine. }\end{array}$ & True & $\begin{array}{c}644 \\
(27.3)\end{array}$ & $\begin{array}{l}1,719 \\
(72.7)\end{array}$ \\
\hline 10 & $\begin{array}{l}\text { If a ward stores Atracurium for tracheal } \\
\text { intubation, the drug should be stored } \\
\text { with other drugs and easily accessed by } \\
\text { nurses }\end{array}$ & False & $\begin{array}{l}1,753 \\
(74.2)\end{array}$ & $\begin{array}{c}610 \\
(25.8)\end{array}$ \\
\hline
\end{tabular}

nurses about the dose calculation in aforementioned diseased population was poor (Lan et al., 2014).

While writing medication order for a particular patient, the clarity of written medication order is the key factor that can contribute to majority of mediations errors. Extreme caution should be taken while prescribing HAMs and defined units must be written in each medication instead of writing ampule or vial. Around $30 \%$ of the study participants were unaware of this regulation which was slightly better than the findings (correct response $=59.7 \%$ ) of Hsaio and colleagues (2010). Zyoud et al. (2019) reported that around $20 \%$ of Palestinian nurses gave incorrect answer to question regarding the use of ampule or vial for dose expression instead of milligram or grams. Regarding the storage, HAMs must carry distinct labeling in order to differentiate them from rest of the medicines. Moreover, "heparin" and "insulin" should not be stored together in a single refrigerator due to chances of their mix up (Belknap, 2001). Around 22\% of our nurses gave incorrect response to the aforementioned drugs which was similar to the findings of earlier studies (Hsaio et al., 2010; Lo et al., 2013; Zyoud et al., 2019). Similarly, atracurium can cause severe respiratory depression. Therefore, it must be separated from rest of the ward medicines in refrigerator, in separate box with clear labeling. Since spoons vary in sizes, they cannot be used to measure the accurate amount of medications. However, higher proportion ( $81 \%)$ of the study sample were unaware about the inappropriateness of spoon for pediatric dose measurement which was significantly higher than the findings of previous studies (Hsaio et al., 2010; Zyoud et al., 2019). Inadequacies in the knowledge of HAMs regulation and administration can be attributed to not obtaining extensive HAMs training. None of the study participants reported receiving extensive HAMs trainings in
TABLE 4 | Comparisons of high alert medications administration and high alert medications regulation scores among different demographic variables.

\begin{tabular}{|c|c|c|c|c|}
\hline Variables & $\begin{array}{l}\text { HAM administration } \\
\text { score (mean rank) }\end{array}$ & p-value & $\begin{array}{l}\text { HAM regulation } \\
\text { score (mean } \\
\text { rank) }\end{array}$ & $p$-value \\
\hline Age (years) & & 0.797 & & 0.867 \\
\hline$\leq 25$ & $1,184.45$ & & $1,194.81$ & \\
\hline$>25-30$ & $1,185.95$ & & $1,169.03$ & \\
\hline$>30-35$ & $1,191.47$ & & $1,180.65$ & \\
\hline$>35$ & $1,148.13$ & & $1,199.26$ & \\
\hline Hospital type & & 0.435 & & 0.010 \\
\hline THQ hospital & $1,204.50$ & & $1,199.15$ & \\
\hline DHQ hospital & $1,205.30$ & & $1,109.89$ & \\
\hline $\begin{array}{l}\text { Teaching } \\
\text { hospital }\end{array}$ & $1,168.33$ & & $1,207.21$ & \\
\hline $\begin{array}{l}\text { Working } \\
\text { department }\end{array}$ & & 0.172 & & 0.524 \\
\hline Cardiac & $1,250.51$ & & $1,197.48$ & \\
\hline Dialysis & $1,143.54$ & & $1,241.20$ & \\
\hline Emergency & $1,145.29$ & & $1,174.59$ & \\
\hline Gynea & 1,196.02 & & $1,159.08$ & \\
\hline Labor room & $1,209.24$ & & $1,034.19$ & \\
\hline Medical & $1,137.37$ & & $1,216.43$ & \\
\hline $\begin{array}{l}\text { Operation } \\
\text { theatre }\end{array}$ & $1,199.17$ & & $1,187.39$ & \\
\hline Paeds & $1,276.45$ & & $1,203.34$ & \\
\hline Surgery & $1,125.84$ & & $1,101.00$ & \\
\hline Training & & 0.991 & & 0.919 \\
\hline $\begin{array}{l}\text { Basic life } \\
\text { support }\end{array}$ & $1,205.57$ & & $1,242.53$ & \\
\hline $\begin{array}{l}\text { Emergency } \\
\text { room training }\end{array}$ & $1,195.53$ & & $1,185.75$ & \\
\hline $\begin{array}{l}\text { Infection } \\
\text { control }\end{array}$ & $1,169.99$ & & $1,159.38$ & \\
\hline Midwifery & $1,209.46$ & & $1,177.07$ & \\
\hline $\begin{array}{l}\text { Operation } \\
\text { theatre }\end{array}$ & $1,197.45$ & & $1,147.25$ & \\
\hline $\begin{array}{l}\text { Personal } \\
\text { protective } \\
\text { equipment }\end{array}$ & $1,158.82$ & & $1,169.46$ & \\
\hline $\begin{array}{l}\text { Nursery } \\
\text { (Neonatal ICU) }\end{array}$ & $1,156.17$ & & $1,146.07$ & \\
\hline No training & $1,177.75$ & & $1,191.74$ & \\
\hline Designation & & 0.332 & & 0.841 \\
\hline Staff nurse & $1,178.88$ & & $1,182.64$ & \\
\hline Head nurse & $1,238.91$ & & $1,170.28$ & \\
\hline Qualification & & 0.910 & & 0.402 \\
\hline Bachelor & $1,181.70$ & & $1,179.76$ & \\
\hline Master & $1,189.94$ & & $1,240.72$ & \\
\hline $\begin{array}{l}\text { Experience } \\
\text { (years) }\end{array}$ & & 0.885 & & 0.118 \\
\hline$\leq 2$ & $1,187.09$ & & $1,239.79$ & \\
\hline$>2-4$ & $1,203.40$ & & $1,162.24$ & \\
\hline$>4-6$ & $1,174.41$ & & $1,129.91$ & \\
\hline$>6-8$ & $1,182.24$ & & $1,136.30$ & \\
\hline$>8-10$ & $1,156.35$ & & $1,127.50$ & \\
\hline$>10$ & $1,158.75$ & & $1,213.64$ & \\
\hline
\end{tabular}

$D H Q$, District Headquarter; HAM, High alert medication; ICU, Intensive care unit; $T H Q$, Tertiary Headquarter.

the present study which can be attributable to the severe shortage of clinical pharmacists in Pakistani health settings. Studies from Taiwan (mean 64.6 vs 54.6, $\mathrm{p}<0.01$ ) and Palestine (median 65 vs $50, \mathrm{p}=0.002)$ reported that HAMs trainings were associated with 
TABLE 5 | Barriers encountered during administration of high alert medication.

\begin{tabular}{llc}
\hline No. & \multicolumn{1}{c}{ Obstacles } & N (\%) \\
\hline 1 & Insufficient knowledge & $807(34.1)$ \\
2 & Have to accept oral order & $1,314(55.6)$ \\
3 & Confused prescription & $1,029(43.5)$ \\
4 & Inconsistent opinions between nurses & $828(35.0)$ \\
5 & Inconsistent opinions between doctor and nurse & $1,206(51.0)$ \\
6 & No reference for drug use & $766(32.4)$ \\
7 & Receive uncertain answers from colleagues & $1,724(72.9)$ \\
8 & Unclear dose calculation & $910(38.5)$ \\
9 & No established standard operating procedures for high alert & $867(36.7)$ \\
& medications & \\
10 & No rigorous regulations for high alert medication & $1,005(42.5)$ \\
11 & Mix high alert medications with other drugs & $835(35.3)$ \\
12 & Easy access to high alert medications & $898(38.0)$ \\
13 & No suitable person to consult & $1,444(61.1)$ \\
\hline
\end{tabular}

better knowledge (Hsaio et al., 2010; Zyoud et al., 2019). We strongly endorse the recommendation of Lo et al. (2013) regarding the inclusion of classes on the HAMs subject as a part of formal, in-school nursing education, as well as of hospital-based continuing education. Moreover, there is a dire need to bridge the gaps between physicians, clinical pharmacists, and nurses (Table 5) through effective communication. This will help reduce medication errors and improve patient care. Additionally, as there is a very high deficit of qualified and skilled healthcare workers, particularly nurses and midwives (FDGOP, 2019), Govt. should take measures necessary to improve the strength of nurses, doctors, and pharmacists in Pakistani hospitals.

\section{CONCLUSIONS}

The current study revealed the serious inadequacies in HAMs knowledge among Pakistani nurses which can cause medication errors leading to adverse patient outcomes. Major obstacles faced by nurses during HAMs administration were "getting uncertain answers from colleagues," "unavailability of suitable person to consult," and "receiving verbal orders." Nursing students should receive comprehensive HAMs related education and training during graduation. Moreover, the training of the nursing staff should also

\section{REFERENCES}

92 News (2019). Nine-month-old baby, who was administered wrong injection, laid to rest. 22 April 2019. Available at: https://92newshd.tv/nine-month-old-babywho-administered-wrong-injection-laid-to-rest/\#.XpGJ7EFS_IV.

Aboshaiqah, A. E. (2013). Barriers in reporting medication administration errors as perceived by nurses in Saudi Arabia. Middle-East J. Sci. Res. 17 (2), 130-136. doi: 10.5829/idosi.mejsr.2013.17.02.76110

Agency for Healthcare Research and Quality (2019). Medication Errors and Adverse Drug Events. Available at: https://psnet.ahrq.gov/primer/ medication-errors-and-adverse-drug-events.

Akhideno, P. E., Fasipe, O. J., Isah, A. O., and Owhin, O. S. (2018). Economic burden, impact, and consequence of adverse drug reactions among medical inpatients in clinical practice. J. Clin. Sci. 15 (4), 186-193. doi: 10.4103/ jcls.jcls_64_18

Anger, K. E., Belisle, C., Colwell, M. B., Dannemiller, R., Alawadhi, B., Wilkocki, A., et al. (2014). Safety of Compounded Calcium Chloride Admixtures for Peripheral be conducted on periodic basis. Each health facility in Pakistan must recruit sufficient number of medication experts (clinical pharmacists and pharmacovigilance officers) in order to ensure consultancy and availability of standard operation procedure for high alert medication safe storage, dispensing, and administration.

\section{DATA AVAILABILITY STATEMENT}

The datasets generated during and/or analyzed during the present study are available from the corresponding author (muhammad.salman@pharm.uol.edu.pk, msk5012@gmail.com) on reasonable request.

\section{ETHICS STATEMENT}

This study was approved by the Research Ethics Committee of the Department of Pharmacy Practice, Faculty of Pharmacy, The University of Lahore. As the committee waived the need for written consent, a verbal informed consent was taken from every nurse before the enrollment.

\section{AUTHOR CONTRIBUTIONS}

All the authors contributed equally to this study.

\section{ACKNOWLEDGMENTS}

Authors are grateful to all the study participants for sparing time to fill-out questionnaires.

\section{SUPPLEMENTARY MATERIAL}

The Supplementary Material for this article can be found online at: https://www.frontiersin.org/articles/10.3389/fphar.2020. 01026/full\#supplementary-material

Intravenous Administration in the Setting of a Calcium Gluconate Shortage. J. Pharm. Pract. 27 (5), 474-477. doi: 10.1177/0897190013513617

Aronson, J. K. (2009). Medication errors: definitions and classification. Br. J. Clin. Pharmacol. 67 (6), 599-604. doi: 10.1111/j.1365-2125.2009.03415.x

Belknap, S. (2001). High-alert'medications and patient safety. Int. J. Qual. Health Care 13 (4), 339. doi: 10.1093/intqhc/13.4.339

Bonvin, A., Vantard, N., Charpiat, B., Pral, N., Leboucher, G., Philip-Girard, F., et al. (2009). Accidental intravenous injection of potassium chloride: analysis of contributing factors and barriers to risk reduction. Annales Francaises D'anesthesie Reanim. 28 (5), 436-441. doi: 10.1016/j.annfar.2009.01.014

Chiang, H. Y., Lin, S. Y., Hsu, S. C., and Ma, S. C. (2010). Factors determining hospital nurses' failures in reporting medication errors in Taiwan. Nurs. Outlook 58 (1), 17-25. doi: 10.1016/j.outlook.2009.06.001

Choi, I., Lee, S. M., Flynn, L., Kim, C. M., Lee, S., Kim, N. K., et al. (2016). Incidence and treatment costs attributable to medication errors in hospitalized patients. Res. Soc. Admin. Pharm. 12 (3), 428-437. doi: 10.1016/ j.sapharm.2015.08.006 
Dawn News. (2017). Medication errors cause half a million deaths in Pakistan, say pharmacists. 11 October 2017. Available at: https:/www.dawn.com/news/ 1362951.

Dillon, R. C., Merchan, C., Altshuler, D., and Papadopoulos, J. (2018). Incidence of adverse events during peripheral administration of sodium chloride $3 \%$. J. Intensive Care Med. 33 (1), 48-53. doi: 10.1177/0885066617702590

Dumo, A. M. B. (2012). Factors affecting medication errors among staff nurses: basis in the formulation of medication information guide. IAMURE Int. J. Health Educ. 1 (1), 88-149. doi: 10.7718/iamure.ijhe.v1i1.210

Ferner, R. E., and Aronson, J. K. (2006). Clarification of terminology in medication errors. Drug Saf. 29 (11), 1011-1022. doi: 10.2165/00002018200629110-00001

Finance Division, Government of Pakistan (2019). Pakistan Economic Survey 2018-2019. Available at: http://www.finance.gov.pk/survey/chapters_18/ Economic_Survey_2017_18.pdf.

Formica, D., Sultana, J., Cutroneo, P. M., Lucchesi, S., Angelica, R., Crisafulli, S., et al. (2018). The economic burden of preventable adverse drug reactions: a systematic review of observational studies. Expert Opin. Drug Saf. 17 (7), 681695. doi: 10.1080/14740338.2018.1491547

Geo News (2019). Karachi infant Nashwa died after being administered wrong injection: medical report (May 14 2019). Available at: https://www.geo.tv/latest/ 237315-karachi-infant-nashwa-died-after-being-administered-wronginjection-medical-report.

Hammoudi, B. M., Ismaile, S., and Abu Yahya, O. (2018). Factors associated with medication administration errors and why nurses fail to report them. Scand. J. Caring Sci. 32 (3), 1038-1046. doi: 10.1111/scs.12546

Hsaio, G. Y., Chen, I. J., Yu, S., Wei, I. L., Fang, Y. Y., and Tang, F. I. (2010). Nurses' knowledge of high-alert medications: instrument development and validation. J. Adv. Nurs. 66 (1), 177-190. doi: 10.1111/j.1365-2648. 2009.05164.x

Iftikhar, S., Sarwar, M. R., Saqib, A., and Sarfraz, M. (2018). Causality and preventability assessment of adverse drug reactions and adverse drug events of antibiotics among hospitalized patients: A multicenter, cross-sectional study in Lahore, Pakistan. PloS One 13 (6), e0199456. doi: 10.1371/ journal.pone.0199456

Jafferi, R. (2019). Infant Nashwa, left paralysed due to alleged medical negligence, passes away at Karachi hospital. April 22, 2019. Available at: https://www. dawn.com/news/1477693/infant-nashwa-left-paralysed-due-to-allegedmedical-negligence-passes-away-at-karachi-hospital.

Kim, K. S., Kwon, S. H., Kim, J. A., and Cho, S. (2011). Nurses' perceptions of medication errors and their contributing factors in South Korea. J. Nurs. Manage. 19 (3), 346-353. doi: 10.1111/j.1365-2834.2011.01249.x

Labib, J. R., Youssef, M. R. L., and Abd El Fatah, S. A. (2018). High alert medications administration errors in neonatal intensive care unit: A pediatric tertiary hospital experience. Turkish J. Pediatr. 60 (3), 277-285. doi: 10.24953/turkjped.2018.03.007

Lan, Y. H., Wang, K. W. K., Yu, S., Chen, I. J., Wu, H. F., and Tang, F. I. (2014). Medication errors in pediatric nursing: assessment of nurses' knowledge and analysis of the consequences of errors. Nurse Educ. Today 34 (5), 821-828. doi: 10.1016/j.nedt.2013.07.019

Latimer, S., Hewitt, J., Stanbrough, R., and McAndrew, R. (2017). Reducing medication errors: Teaching strategies that increase nursing students' awareness of medication errors and their prevention. Nurse Educ. Today 52, 7-9. doi: 10.1016/j.nedt.2017.02.004

Lo, T. F., Yu, S., Chen, I. J., Wang, K. W. K., and Tang, F. I. (2013). Faculties' and nurses' perspectives regarding knowledge of high-alert medications. Nurse Educ. Today 33 (3), 214-221. doi: 10.1016/j.nedt.2012.01.004

Makary, M. A., and Daniel, M. (2016). Medical error-the third leading cause of death in the US. BMJ 353, i2139. doi: $10.1136 /$ bmj.i2139
Mrayyan, M. T., Shishani, K., and Al-Faouri, I. (2007). Rate, causes and reporting of medication errors in Jordan: nurses' perspectives. J. Nurs. Manage. 15 (6), 659-670. doi: 10.1111/j.1365-2834.2007.00724.x

Mrayyan, M. T. (2012). Reported incidence, causes, and reporting of medication errors in teaching hospitals in Jordan: A comparative study. Contemp. Nurse 41 (2), 216-232. doi: 10.5172/conu.2012.41.2.216

National Coordinating Council for Medication Error Reporting and Prevention (2015). What is a medication error? (New York, NY: National Coordinating Council for Medication Error Reporting and Prevention). Available at: http:// www.nccmerp.org/about-medication-errors.

Perrone, V., Conti, V., Venegoni, M., Scotto, S., Degli Esposti, L., Sangiorgi, D., et al. (2014). Seriousness, preventability, and burden impact of reported adverse drug reactions in Lombardy emergency departments: a retrospective 2-year characterization. Clin. Econ. Outcomes Res. 6, 505-514. doi: 10.2147/CEOR.S71301

Petrova, E., Baldacchino, D., and Camilleri, M. (2010). Nurses' perceptions of medication errors in Malta. Nurs. Standard (Through 2013) 24 (33), 41. doi: 10.7748/ns2010.04.24.33.41.c7717

Pham, J. C., Aswani, M. S., Rosen, M., Lee, H., Huddle, M., Weeks, K., et al. (2012). Reducing medical errors and adverse events. Annu. Rev. Med. 63, 447-463. doi: 10.1146/annurev-med-061410-121352

Reeve, J. F., Allinson, Y. M., and Stevens, A. (2005). High-risk medication alert: intravenous potassium chloride. Aust. Prescrib. 28 (1), pp.14-pp.16. doi: 10.18773/austprescr.2005.010

Roughead, L., Semple, S., and Rosenfeld, E. (2013). Literature review: medication safety in Australia (Sydney: Australian Commission on Safety and Quality in Health Care).

Shamim, S., Sharib, S. M., Malhi, S. M., Muntaha, S. U., Raza, H., Ata, S., et al. (2016). Adverse drug reactions (ADRS) reporting: awareness and reasons of under-reporting among health care professionals, a challenge for pharmacists. SpringerPlus 5 (1), 1778. doi: 10.1186/s40064-016-3337-4

Shen, L., Yan, J., Xin, X., and Sun, Z. (2018). Cognition of high-alert medication knowledge of clinical nurses and improvement measures to eradicate medication errors. Biomed. Res S370-73. doi: 10.4066/biomedicalresearch.29-17-1491

Topcu, I., Türkmen, A. S., Sahiner, N. C., Savaser, S., and Sen, H. (2017). Physicians' and nurses' medical errors associated with communication failures. J. Pakistan Med. Assoc. 67 (4), 600-604.

Tshiamo, W. B., Kgositau, M., Ntsayagae, E., and Sabone, M. B. (2015). The role of nursing education in preventing medication errors in Botswana. Int. J. Afr. Nurs. Sci. 3, 18-23. doi: 10.1016/j.ijans.2015.06.001

World Health Organization (2016). Medication Errors: Technical Series on Safer Primary Care. Licence: CC BY-NC-SA 3.0 IGO. Available at: https://apps.who. int/iris/bitstream/handle/10665/252274/9789241511643-eng.pdf;jsessionid= FDB1BE2683396D2DA592F947714EBF5E?sequence=1.

Zyoud, H. S., Khaled, S. M., Kawasmi, B. M., Habeba, A. M., Hamadneh, A. T., Anabosi, H. H., et al. (2019). Knowledge about the administration and regulation of high alert medications among nurses in Palestine: a crosssectional study. BMC Nurs. 18 (1), 11. doi: 10.1186/s12912-019-0336-0

Conflict of Interest: The authors declare that the research was conducted in the absence of any commercial or financial relationships that could be construed as a potential conflict of interest.

Copyright (C) 2020 Salman, Mustafa, Rao, Khan, Asif, Hussain, Shehzadi, Khan and Rashid. This is an open-access article distributed under the terms of the Creative Commons Attribution License (CC BY). The use, distribution or reproduction in other forums is permitted, provided the original author(s) and the copyright owner(s) are credited and that the original publication in this journal is cited, in accordance with accepted academic practice. No use, distribution or reproduction is permitted which does not comply with these terms. 